\title{
A MORTE DO AUTTOR um retorno à cena do crime
}

RESUMO: A partir do século XVIII, a função autoral afasta-se daquela vigente no Medievo e na Renascença na medida em que o "autor" passa a ser historicamente compreendido como proprietário de textos originais que, dadas as condições institucionais adequadas, podem ser ideologicamente naturalizados e legitimados por valores universalizantes que atendem tanto a exigências culturais como mercadológicas. É esse processo ideológico de naturalização, particularmente visível em autores canônicos como William Shakespeare e James Joyce, que é radicalmente questionado pela crítica pós -estruturalista a partir da década de 1960. Em "A morte do autor", Barthes percebe no texto, agora pensado enquanto tecido de citações, precisamente aquele local de diluição de autores, origens e presenças no qual o sujeito autoral desaparece. Em “O que é um autor?”, Foucault expande e qualifica a proposta de Barthes ao insistir na necessidade de suplementar a mera afirmação do desaparecimento do autor com um estudo sistemático da dinâmica de sua morte e ressurreição no espaço textual. O questionamento da função autoral nos dois autores pode ser ainda hoje lido com proveito na medida em que deixa entrever a proposta de uma ética alternativa da leitura capaz de ir além do modo de ler que tem no autor uma modalidade controladora do discurso.

PALAVRAS-CHAVE: morte do autor, Foucault, Barthes, ética da leitura.
ABSTRACT: After the 18th Century, the authorial function distances itself from the one existing in the Middle Ages and the Renaissance in that the author becomes historically the owner of original texts that, given the appropriate institutional conditions, can be ideologically naturalized in terms of universal values that respond to cultural and market demands. It is this process of naturalization, particularly visible in canonic authors such as William Shakespeare and James Joyce, that is profoundly challenged by post-structuralist theories after the 1960s of the last century. In "The death of the author", Barthes sees the text, now understood as a texture of citations, as precisely that locus of dissolution of authors, origins and presences in which the authorial subject disappears. In "What is an author?", Foucault expands on and qualifies Barthes's proposal by insisting on the necessity to supplement the simple affirmation of the disappearance or the author with a systematic study of the dynamics of her death and resurrection in the textual space. The questioning of the authorial function in the two authors can still be relevant today insofar as it allows us to entertain the possibility of an alternative ethics of reading that can go beyond the mode of reading that sees the author as a controlling discursive force.

KEYWORDS: death of the author, Foucault, Barthes, ethics of reading.

\section{đutoria e Singularidade Histórica}

Em "A morte do autor", Roland Barthes situa certeiramente a figura autoral em sua historicidade. Trata-se de

\begin{abstract}
[...] uma personagem moderna, produzida sem dúvida por nossa sociedade na medida em que, ao sair da idade média, com o empirismo inglês, o racionalismo francês e a fé pessoal da reforma, ela descobriu o prestígio do indivíduo ou, como se diz mais nobremente, da "pessoa humana”. Então é lógico que, em matéria de literatura, seja o positivismo, resumo e ponto de chegada da ideologia capitalista, que tenha concedido a maior importância à "pessoa” do autor. (BARTHES 2004b, p. 58)
\end{abstract}

São as forças culturais da modernidade, portanto, que fabricam a função autoral em termos de um aparato que atende a demandas do momento, de uma ideologia que oculta condições de produção e ${ }^{1}$ Professor Titular de Teoria Literária na Universidade Federal de Minas Gerais. Contato: belleis@terra.com.br 
naturaliza significados e de uma força produtiva que motiva práticas sociais, econômicas e políticas. Enquanto fabricação cultural, o autor nasce e morre no fluxo temporal, ainda que a designação autoral permaneça a mesma. Em sua especificidade, o autor que surge como proprietário de textos originais a partir do século XVIII difere significativamente do autor renascentista e do autor medieval. A força ideológica que vai, aos poucos, naturalizando o seu sentido histórico, acaba por consolidá-lo como valor universal. É nesse contexto que, digamos, tanto James Joyce como William Shakespeare, separados por três séculos, podem ser identificados como “autores”. Acompanha esse processo de naturalização e universalização, finalmente, um acúmulo de poder institucional que propulsiona o mercado editorial, a sacralização do gênio e da obra clássica e a disseminação de textos canônicos.

O caso de Shakespeare ilustra exemplarmente os postulados aqui esquematicamente apresentados. Andrew Bennet deu-se ao trabalho de comparar o número de ocorrências do termo "autor" na obra completa do bardo com a sua contrapartida no script do filme Shakespeare in Love. O resultado não deixa de surpreender, pelo menos aparentemente: no breve texto do filme (23.000 palavras) o termo aparece sete vezes, na obra completa do bardo (cerca de 880.000 palavras), apenas seis vezes (BENNET, 2005, p. 1). Evidentemente, a questão da autoria tem, no filme e em nossos dias, um significado diverso daquele vigente no século XVI, quando a pergunta feita no filme por Viola, a suposta amante secreta do bardo ("É você o autor das peças de William Shakespeare?”) seria inimaginável. O filme de 1998, em outras palavras, trabalha não apenas a temática da vida e obra ao "autor" (e também ator) inglês, mas também aquela obsessão cultural contemporânea com questões autorais que pode bem ajudar a entender a reação fóbica que surge quase inevitavelmente quando se fala na "morte do autor". Enquanto são apresentados ao telespectador os créditos iniciais do filme, como lembra Bennet, "Will aparece, momentaneamente, exercitando-se em versões diversas de suas assinaturas" e o título do filme apresenta-se "superposto a uma folha de papel em que estão inscritas as diversas variantes no nome manuscrito de William" (BENNET, 2005, p. 2). O que o filme sugere, Bennet conclui, é que Shakespeare "tinha o mesmo interesse que temos hoje na natureza do seu nome, na sua própria identidade, e na forma como tal identidade seria percebida” (BENNET, 2005, p. 2).

Falando do passado, portanto, o filme nele insere a história do presente como se tivessem ambas as mesmas obsessões e fobias e, nesse processo de homogeneização temporal, universaliza e naturaliza o conceito de "autor" em uma operação ideológica que não resiste a um olhar histórico mais rigoroso. Mark Rose observa que, quando Shakespeare utiliza o termo "autor", nos epílogos de Henry IV e Henry V, a palavra tem o sentido de "fonte" ou de "aquele que dá origem a alguma coisa" (ROSE, 1993, p. 26). A caracterização do dramaturgo como "criador e proprietário de uma obra original e genial" só seria inventada posteriormente, em momentos históricos marcados por demandas culturais, econômicas e políticas diversas. No século XVI e no início do século XVII, o produtor de peças teatrais não era um "autor" no sentido atual do termo, mas um membro acionário do Globe Theatre, atuando como um colaborador na empreitada coletiva de produzir obras dramáticas que, com raras exceções, eram reproduzidas a partir de narrativas populares da Idade Média e da Renascença.

Percebendo-se como produtor de peças para consumo imediato mais do que um escritor a ser canonizado, o próprio Shakespeare não se deu ao trabalho de publicar sua obra dramática. Rose (1993, p.26) conclui que não seria inteiramente descabido "caracterizar o dramaturgo (mas não o autor de sonetos e poemas) como um reprodutor de histórias em um sentido quase medieval”. O complexo processo histórico que vai, aos poucos, reinventando o adaptador de histórias tradicionais como um autor de obras originais e um gênio universal deve, de acordo com Rose, ser entendido como inseparável de outros processos históricos, como o que leva à criação de leis de direitos autorais. Estas são constituídas com o objetivo de estabelecer mecanismos de controle comercial da intensa proliferação de livros nos séculos XVII e XVIII 
e dependem, para tanto, da institucionalização do autor proprietário de sua obra e da consolidação dos conceitos de "originalidade" e "cópia”.

Um reforço ao conceito de autor proprietário de obras originais apareceria mais tarde, com a utilização da categoria romântica de "gênio", a ser atribuída a alguns proprietários de obras com a finalidade de valorização máxima dos produtos, tanto em termos literários como mercadológicos, muito embora estes últimos não pudessem ser confessados abertamente. Não custa lembrar que, como observou Terry Eagleton, a representação do escritor como gênio transcendental aparece, justamente, "no momento em que o artista se vê transformado em um produtor de mercadorias pouco competitivas”, o que torna possível entender a invenção do conceito como uma "compensação espiritual pela degradação" operada por forças de mercado (EAGLETON, 1990, p. 64-65).

O processo de fabricação histórica do autor moderno vem normalmente acompanhado da produção e da circulação de energias socioculturais. O caso de Shakespeare é, mais uma vez, exemplar. A construção da narrativa que transforma Shakespeare em um autor individual de obras originais tem como um de seus componentes a sacralização de Stratford-upon-Avon, a terra natal do bardo. Mark Rose registra que, a partir de 1740, "peregrinos começam a visitar Stratford à procura de relíquias do dramaturgo. Estas eram convenientemente produzidas por Thomas Sharpe, que vendia fragmentos de uma árvore da qual era proprietário e que fora supostamente plantada por Shakespeare. Em 1769, antes da cerimônia do jubileu do bardo, os leitores do Gentleman's Magazine foram convidados a marchar para Stratford, “como se fossem peregrinos em busca do altar de um santo". E como parte da cerimônia, o ator David Garrick propôs um brinde com um cálice feito com madeira extraída da árvore de Thomas Sharpe:

\section{Contemplai todos o cálice, do tronco lavrado, \\ Que foi por ti, gentil Shakespeare, plantado; \\ Beijo a relíquia, e frente ao altar me inclino; \\ Pois o que tua mão escreve é para sempre divino.}

(ROSE, 1993, p. 123)

Liberação de energia sociocultural semelhante à de Shakespeare ocorreria novamente três séculos depois, ou seja, ainda no período histórico de vigência hegemônica do que conhecemos como "o autor moderno". Trata-se do "Bloomsday”, celebração realizada anualmente (no dia 16 de junho de 1904, a data em que Leopold Bloom caminha pelas ruas de Dublin no Ulysses), em homenagem a James Joyce e à sua obra. No caso de Joyce, a celebração supera aquela dedicada a Shakespeare porque ocorre em escala planetária. Curiosamente, detalhes do primeiro Bloomsday em Dublin assemelham-se às ocorrências do jubileu de Shakespeare. A celebração, organizada em 16 de junho de 1954 por cinco admiradores de Joyce, consistia na realização de uma romaria pelas ruas de Dublin, imitando o trajeto de Leopold Bloom. O poeta Patrick Kavanagh deixou registrada sua participação no evento:

Peregrino caminhei

No calor do Bloomsday

A Torre Martello deixei

Na central dos coches parei. (IGOE, 2001, p. 82) 


\section{Roland Barthes: Teoria, História e Desejo}

O interesse de Barthes na questão do autor não se limita ao celebrado ensaio sobre "A morte do autor" (1967). Prepara o caminho para o texto de 1967, por exemplo, o estudo Sur Racine (1963), que aponta para a necessidade de uma crítica capaz de ir além dos estudos tradicionais do autor e sua obra. E a preocupação com a instituição autoral retornaria posteriormente, por exemplo, em Sade, Fourier, Loyola (1971), em que o prazer do texto não descarta a possibilidade de um certo retorno do autor, muito embora esse autor seja agora pensado mais em termos de uma pluralidade do que de uma unidade. Mas não seria descabido dizer que é no ensaio de 1967 que a questão autoral se manifesta, por assim dizer, em sua forma mais contundente, pura e, principalmente, desarmada em termos daquele rigor teórico que transformou o texto, simultaneamente, em um marco fundamental para a teoria literária e em um objeto de questionamentos.

Em “A morte do autor", publicado por Barthes em inglês no periódico norte-americano Aspen, em 1967, a dimensão que adquire maior visibilidade é aquela de uma teoria que pretendia ser, na época, nova e revolucionária. A proposta era questionar radicalmente toda e qualquer origem em função do entendimento do texto enquanto espaço não unificado de dispersão e disseminação de significados fora de controle. Um texto passa, portanto, a ser visto como um intertexto que nenhum autor pode controlar porque cada significado alude não a um ou mais sentidos específicos (ou seja, a uma pluralidade controlável de significados), mas a uma multiplicidade sem limites porque desprovida de centro ou origem. O texto, dirá Barthes em ensaio posterior ("Da obra ao texto") "pratica o recuo infinito do significado" (BARTHES, 2004a, p. 69). Ora, um texto que resiste à domesticação não apenas reduz o poder de quem o escreve, mas acaba por assumir o controle sobre ele. Já não se pode dizer que o autor é o sujeito que fala. É a linguagem que fala através dele.

A proposta é revolucionária principalmente porque se insurge contra o cogito cartesiano que Jacques Lacan já havia questionado em texto de 1966. Aceito o pensamento da textualidade sem centro, tornava-se necessário substituir o cogito ergo sum por ubi cogito ergo sum (p. 275). No segundo cogito, evidentemente, o "eu" desaparece ou morre ao se tornar um efeito do pensamento ou da linguagem. No ensaio de Barthes, é um texto de Balzac que serve para ilustrar a questão. Citando uma frase que apresenta a protagonista de Sarrasine (um castrado disfarçado de mulher), Barthes indaga a respeito de quem poderia ser o autor da descrição e conclui pela impossibilidade de sua determinação, já que a voz que fala não pode ser identificada nem com o "herói da novela”, nem com o "indivíduo Balzac", nem com a "sabedoria universal” e nem com a "psicologia romântica”. Barthes conclui:

Não será jamais possível saber, pela simples razão que a escritura é a destruição de toda voz, de toda origem. A escritura é esse neutro, esse composto, esse oblíquo pelo qual foge o nosso sujeito, o branco-e-preto em que vem se perder toda identidade, a começar pela do corpo que escreve. (BARTHES, 2004b, p. 57)

O questionamento das tradições consolidadas do sujeito e do autor não se faz sem dificuldades. No próprio texto de Barthes, essas dificuldades não deixam de se manifestar e acabam por tornar problemático o uso do termo "morte" no título do ensaio. Teorias literárias anteriores e mais convencionais já tinham percebido a possibilidade do desaparecimento do autor no texto sem, contudo, decretar a sua morte. É o caso, por exemplo, do conceito de "autor implícito" (implied author) proposto por Wayne C. 
Booth no livro The Rhetoric of Fiction (1961). Entidade distinta tanto do autor como do narrador, o autor implícito é constituído pelo leitor com base na forma como o texto é estruturado:

O sentido que apreendemos do autor implícito inclui não apenas os significados obtidos do texto, mas também o conteúdo moral e emocional de cada elemento de ação e de sofrimento de todos os personagens. Inclui, em resumo, a apreensão de um todo artístico completo; o valor maior legitimado por esse autor implícito, a despeito das posições ideológicas do autor na vida real, é aquele expresso pela forma total. (BOOTH, 1983, p. 74)

É bem possível que o uso da expressão "morte do autor", em Barthes, seja motivado mais por um desejo de radicalização de uma teoria que se quer nova do que pelo rigor teórico que seria de se esperar de um expoente maior do pensamento francês da época. É nesse contexto que a conclusão do ensaio acaba por qualificar e enfraquecer a proposta de "morte", apresentada no início em termos da dissolução de origens e unidades totalizantes causada pelo intertexto desprovido de centros, inícios ou finais. Essa presença central do autor que origina textos ressurge no final do ensaio e não deixa de ter, curiosamente, certas semelhanças com o "autor implícito" de Booth. "O nascimento do leitor" diz Barthes, "deve pagarse com a morte do Autor" (BARTHES, 1968b, p. 64). Apesar do uso da maiúscula para diferenciar o autor do leitor, não deixam ambos de ter semelhanças profundas, uma vez que é ele, o leitor,

\footnotetext{
[...] o espaço mesmo onde se inscrevem, sem que nenhuma se perca, todas as citações de que é feita uma escritura: a unidade do texto não está em sua origem, mas no seu destino, mas esse destino já não pode ser pessoal: o leitor é um homem sem história, sem biografia, sem psicologia; ele é apenas esse alguém que mantém reunidos em um mesmo campo todos os traços de que é constituído o escrito. (BARTHES, 2004b, p. 64)
}

Muito embora haja aqui um esforço para esvaziar esse leitor das marcas clássicas do humanismo tradicional (a sua biografia, história e psicologia), não deixa ele de constituir-se precisamente como o autor: um sujeito definido como origem e centro produtor de sentidos a serem unificados em um processo de leitura que deve cobrir todos os traços do texto a ser lido. Não é outra, diga-se de passagem, a função do leitor que constitui o "autor implícito" em Booth. Assassinado na porta de entrada do ensaio, o autor, por assim dizer, retorna pela porta dos fundos. Sua condição é menos a de um morto do que a de um mortovivo ou de um espectro que retorna.

Por quê as inconsistências no ensaio de Barthes? A história da publicação do texto talvez ajude a entender a questão. Embora o ano de 1968 seja com frequência citado como a data de publicação (quando apareceu na revista Manteia, vol 5, $\mathrm{n}^{\circ}$ 4), trata-se de um equívoco. O ensaio, na realidade, foi apresentado em um simpósio realizado em 1967 e publicado nos Estados Unidos, em inglês, no periódico Aspen (vol. 5-6). Tratava-se de um periódico de caráter experimental, iconoclasta e vanguardista. Como explica Andrew Bennet, o volume que incluiu o ensaio de Barthes consistia, na realidade, de uma "caixa contendo vinte e oito artefatos, incluindo filmes, discos, diagramas, recortes feitos em papelão e textos convencionais". Dedicado a Mallarmé, a publicação tinha como contribuintes, entre outros, "Marcel Duchamp, Alain Robbe-Grillet, Michel Butor, Merce Cunningham, Samuel Beckett e John Cage. (BENNET, 2005, p. 7, 13-14). O tom de manifesto que caracteriza com frequência os discursos de vanguarda justificaria, talvez, os tropeços argumentativos. 
Seja como for, a figura do autor, agora desprovida da unidade tradicional atribuída ao sujeito que escreve e apresentada em um contexto de forças históricas que estão longe de operar unicamente em benefício da humanidade, é desmascarada e perde significativamente sua força cultural. Uma vez percebida em seu íntimo relacionamento com a ênfase na produtividade capitalista, a concepção humanista do indivíduo e do autor adquire tons sombrios e perturbadores. No limite, Barthes verá em tais forças a marca da tirania: "a imagem da literatura que se pode encontrar na cultura corrente está tiranicamente centralizada no autor, sua pessoa, sua história, seus gostos, suas paixões” (BARTHES, 2004b, p. 58). Descontado o tom contundente típico da publicação de 1967, o uso do termo não é de todo descabido. Associada à constatação de tal tirania, aparece no texto de Barthes um desejo de libertação a ser obtido na conceituação de uma intertextualidade aberta e de um leitor produtor de sentidos que se opõem à obra e aos leitores tradicionais.

\section{IIIichel Foucault e a Função Autoral}

O ensaio de Michel Foucault, “O que é um autor?” (1969) complementa e problematiza o texto de Barthes principalmente porque, ao enfatizar as dimensões históricas, econômicas e sociais do conceito de "autor", consegue entender com mais rigor o que poderia significar a morte da figura autoral em uma dinâmica de aparecimento e desaparecimento. "Não basta", diz Foucault, "repetir perpetuamente como afirmação vazia que o autor desapareceu”. Para além do desaparecimento, é preciso "localizar o espaço assim deixado vago pela desaparição do autor, seguir atentamente a repartição das lacunas e das falhas e espreitar os locais, as funções livres que essa desaparição faz aparecer” (FOUCAULT, 2009, p. 271).

É preciso, em outras palavras, estudar a função autoral em suas quatro características fundamentais: como "forma de propriedade" historicamente codificada no "final do século XVIII e no início do século XIX" (FOUCAULT, 2009, p. 274-275); como forma também historicamente codificada de diferenciação de origens discursivas, de forma a estabelecer a distinção, por exemplo, entre o autor moderno e o autor medieval; como forma de diferenciação entre práticas discursivas em um momento histórico, estabelecendo distinções, por exemplo, entre um "autor filosófico" e um "poeta” (FOUCAULT, 2009, p. 277); e, finalmente, como força discursiva capaz de constituir uma pluralidade de posições autorais que permite diferenciar em um romance, por exemplo, "o relato de um narrador" enquanto um "alter ego" cuja distância em relação ao escritor pode ser maior ou menor e variar ao longo da mesma obra” (FOUCAULT, 2009, p. 279). Com respeito a essa última função autoral, diga-se de passagem que Foucault, consciente ou inconscientemente, valoriza e legitima percepções teóricas anteriores que, em Barthes, são ignoradas. A descrição de um "alter ego" do autor no interior de uma narrativa assemelha-se ao que Booth chamara anteriormente de "implied author".

Em Foucault, contudo, a proposta de uma leitura teórica alternativa da morte do autor não significa uma discordância radical em relação ao texto de Barthes. Também em Foucault, a figura autoral não deixa de estar associada a uma certa tirania, já que "o autor é a figura ideológica pela qual se afasta a proliferação de sentido" (FOUCAULT, 2009. p. 288). A ideologia é aqui entendida no sentido proposto por Marx em A Ideologia Alemã, ou seja, é uma produção discursiva mistificadora que projeta uma imagem invertida do real (MARX; ENGELS, 2001, p. 19). “A ideologia existe”, explica didaticamente Terry Eagleton, "porque há certas coisas que não devem ser ditas" (EAGLETON, 1976, p. 91). O sentido de "autor" que pode ser dito sem causar desconforto é aquele que o define como uma "instância criadora que emerge de uma obra em que ele deposita, com uma infinita riqueza e generosidade, um mundo inesgotável de significações” (FOUCAULT, 2009, p. 288). Para Foucault, a verdade é “completamente diferente”: 
Se temos o hábito de apresentar o autor como gênio, como emergência perpétua de novidade, é porque na realidade nós o fazemos funcionar de um modo exatamente inverso. Diremos que o autor é uma produção ideológica na medida em que temos uma representação invertida de sua função histórica real. (FOUCAULT, 2009, p. 288)

A necessidade do autor está, portanto, associada à fobia cultural da proliferação e disseminação desordenada e descontrolada de sentidos. Constituindo-se como proprietário de uma obra em que limites são precisamente definidos por comunidades de poder institucional (como, por exemplo, aquelas formadas por editores, críticos e acadêmicos), "o autor torna possível uma limitação da proliferação cancerígena, perigosa das significações em um mundo onde se é parcimonioso não apenas em relação aos seus recursos e riquezas, mas também aos seus próprios discursos e suas significações” (FOUCAULT, 2009, p. 287).

Embora entendendo o autor enquanto força repressiva do discurso, Foucault evita repetir o gesto utópico do Barthes que sonha com o desaparecimento da tirania autoral. "Seria puro romantismo", afirma, "imaginar uma cultura em que a ficção circularia em estado absolutamente livre, à disposição de cada um, desenvolver-se-ia sem atribuição a uma figura necessária ou obrigatória” (FOUCAULT, 2009, p. 288). Pertencendo ao devir histórico, a função autoral pode mudar de forma, mas dificilmente desaparecerá. Poderá "funcionar de novo de acordo com um outro modo, mas sempre segundo um sistema obrigatório que não será mais o do autor, mas que fica ainda por determinar e talvez por experimentar" (FOUCAULT, 2009, p. 288). Subjacente a essa afirmação está o Foucault que formulou uma teoria do poder onipresente que preenche todo e qualquer espaço. Se uma forma de poder desaparece em certo momento histórico, ressurgirá de outra forma mais adiante. Resta saber se outras eventuais formas de poder "por determinar" seriam menos opressivas, e portanto mais desejáveis, do que o poder autoral.

\section{Barthes, Foucault e a Ética da Leitura}

Definido como modalidade controladora do discurso, o autor torna-se necessariamente também uma forma de controle do leitor e a ele impõe uma ética de leitura. É no questionamento dessa ética imposta que os textos de Barthes e, principalmente, de Foucault, podem ser ainda hoje estudados com proveito. Em Barthes, essa ética de leitura atribui ao leitor a liberdade radical de constituir sentidos que já não dependem do controle do autor proprietário do texto. "Dar ao texto um autor", diz Barthes, "é impor-lhe um travão, é provê-lo de um significado último, é fechar a escritura” (BARTHES, 2004b, p. 63). Recuperar esse significado último em cada construção de um ato interpretativo (a interpretação sendo aqui entendida como forma de controle do texto) que fixa e unifica, ainda que apenas por um momento, um sentido textual é o princípio ético básico do crítico e do leitor tradicionais.

A concepção de autor é, nesse contexto, conveniente e necessária para a atividade do crítico que tem como objetivo "descobrir o Autor (ou as suas hipóstases: a sociedade, a história, a psique, a liberdade) sob a obra" (BARTHES, 2004b, p. 63). A existência da crítica depende da autoridade do autor: "encontrado o autor, o texto está explicado, o crítico venceu” (BARTHES, 2004b, p. 63). Morto o autor e suas hipóstases, essa ética interpretativa entraria em crise e deveria ser substituída por uma outra que, para Barthes, poderia ser definida em termos da lógica de leitura que evita controlar o sentido (e, portanto, produzir interpretações) e procura o "prazer do texto".

O texto, para o leitor disposto a praticar essa ética de leitura, "é um espaço de dimensões múltiplas, onde se casam e se contestam escrituras variadas, das quais nenhuma é original: o texto é um tecido de citações, oriundas dos mil focos da cultura” (BARTHES 2004b, p. 62). E a prática de leitura solicitada por 
tal texto desprovido da mensagem do "Autor-Deus" é aquela que seleciona para leitura alguns dos fios desse tecido, evitando todo e qualquer impulso dirigido para totalizações de sentido.

Um dos textos utilizados por Barthes para exemplificar essa prática de leitura é o conto "A verdade sobre o caso do Sr. Valdemar”, de Edgar Allan Poe. Transferida a autoridade autoral do Autor-Deus-Poe para o Barthes-leitor, pode este explorar o plural do texto em seus vários códigos culturais sem jamais chegar a um sentido final. O interdito imposto à produção do sentido final é uma consequência da definição de texto proposta: “o texto não é uma estrutura interna, fechada, contabilizável, mas o desembocar do texto noutros textos, noutros códigos, noutros signos; o que faz o texto é o intertextual (BARTHES, 2001, p. 307). O procedimento analítico consiste em recortar o texto em segmentos curtos e arbitrariamente definidos ("lexias") para neles observar "os sentidos... suscitados" sem que haja, contudo, qualquer pretensão de esgotar possibilidades de significado (BARTHES, 2001, p. 306). "O que nos importa”, diz Barthes, "é mostrar pontos de partida dos sentidos, não pontos de chegada” (BARTHES, 2001, p. 307).

Tomando como ponto de partida, por exemplo, o nome próprio "Sr. Valdemar", Barthes inicia a procura não teleológica de sentidos e códigos: o termo "senhor" aponta para um código social, já que "carrega um efeito de realidade social, de real histórico"; em "Valdemar" há um código "sócio-étnico", e a indicação de um enigma para o leitor, uma vez que o nome não é anglo-saxão e o seu significado será revelado mais tarde (Valdemar é polonês); há em Valdemar também um código simbólico importante: significa "o vale do mar" e aponta para um tema recorrente em Poe: "o abismo oceânico, a profundeza marinha... a voragem... que está duas vezes fora da natureza, debaixo das águas e debaixo da terra” (BARTHES, 2001, p. 311).

Qual seria a ética de leitura implícita em tal procedimento analítico? Barthes aponta para uma possível resposta quando define o objetivo da análise textual:

Nosso objetivo não é encontrar $o$ sentido, nem mesmo um sentido do texto, e nosso trabalho não se apresenta como uma crítica literária do tipo hermenêutico (que procura interpretar o texto segundo a verdade que ela acredita estar escondida nele) como é o caso, por exemplo, da crítica marxista ou da crítica psicanalítica. Nosso objetivo é chegar a conceber, a imaginar, a viver o plural do texto, a abertura da significância. (BARTHES, 2001, p. 304-305)

O que está em jogo é uma prática de leitura que, porque quer respeitar o plural do texto, deve desrespeitar duas tradições poderosas na cultura ocidental: a da mimese, que postula a possibilidade de representação ou imitação de aspectos do mundo perceptível, e a da hermenêutica, que propõe teorias possíveis do conhecimento válido. O historiador Hayden White apontou para o poder dessas duas tradições ao lembrar que constituem nada mais, nada menos do que as bases de sustentação do projeto de realismo humanista de compreensão do mundo que, originado pelos gregos, chega ao século XX como força dominante, apesar dos esforços iconoclastas das vanguardas.

Consiste o projeto, basicamente, na defesa intransigente do princípio do realismo mimético e hermenêutico não apenas nas artes e na literatura, mas também na ciência. No século XX, são representantes maiores dessa tradição cultural Erich Auerbach, E. H. Gombrich e Karl R. Popper. É no potencial da mimese, que testa e aperfeiçoa no fluxo temporal modelos ficcionais diversos de representação do mundo, que está a grande conquista da literatura ocidental em seu movimento progressivo que deixa para trás as ficções do mito e desenvolve formas de representação mais próximas do real, ainda que a representação perfeita seja inatingível. Para Auerbach, como explica White, a história do realismo avança "do cancelamento dos poderes míticos enquanto conceitos explicativos em questões sociais e psicológicas” e em 
direção do "cultivo de forças sociais, naturais e psicológicas" enquanto "forças racionais de compreensão intra-histórica” de validade imanente (WHITE, 1972, p. 63).

Na teoria da arte de Gombrich, o desenvolvimento da técnica narrativa (na pintura, na escultura, na literatura) de estruturar e fixar o significado de "um momento no tempo" (sem a interferência de princípios explicativos universais) e a conquista "do espaço autônomo estruturado em perspectiva” tornaram possível a "libertação da imaginação humana de sua "procura mítica por verdades eternas e absolutas". E essa libertação abre caminho para o desenvolvimento "da tarefa mais mundana, mas também mais humanamente vantajosa, de controlar a coleta de informações” (WHITE, 1972, p. 61).

$\mathrm{Na}$ filosofia da ciência, finalmente, Popper envidou esforço heroico para demonstrar que, muito embora a ciência não produza "verdades absolutas nem na investigação da natureza e nem no entendimento da sociedade”, a estratégia por ela desenvolvida para gerar "hipóteses descartáveis" acaba por produzir "descrições cada vez mais elegantes e abrangentes [...] da 'verdadeira' natureza do real” (WHITE, 1972, p. 63). Para os três pensadores, portanto, a ciência, a arte e a literatura ocidentais renunciam ao conhecimento absoluto com o objetivo de levar adiante "o mapeamento cuidadoso e controlado da realidade de forma fragmentária, provisória e evolucionária”. O procedimento é de extrema relevância porque permitiu "a expansão do controle que tem o homem sobre o mundo, seja ele natural ou social" (WHITE, 1972, p. 63). Optar por modelos alternativos de conhecimento que venham a negar a mimese e o poder da imaginação significaria escolher o atraso e o "regresso a formas anteriores, arcaicas, infantis e selvagens de imaginação opressora” (WHITE, 1972. 61).

Se aceitarmos a avaliação de White sobre a hegemonia do realismo humanista na cultura ocidental, então a ética de leitura proposta por Barthes está na contramão da mudança histórica e deve ser exorcizada como perigo a ser evitado. A prática de não se entregar à procura do sentido ou de sentidos seria certamente condenada pelos representantes do viés cultural hegemônico citado por White. Na área de estudos literários, por exemplo, Barthes representaria, para os mestres do realismo humanista, perigo semelhante ao representado por James Joyce: "se abandonarmos o contexto histórico - como faz Joyce - estaremos caminhando em direção ao desastre” (WHITE, 1972, p. 63). O jogo intertextual desprovido da procura pela origem e pelo centro seria mais um momento de decadência cultural em que o jogo da linguagem substitui a verdadeira procura pelo conhecimento.

Em seu prefácio ao "Rumor da Língua”, publicado em 1988, Leyla Perrone Moisés observa que, “oito anos depois de sua morte, o mestre do saber com sabor anda um pouco esquecido" e atribui "essa espécie de purgatório ou de limbo a que Barthes foi relegado" a dois fatores: "a lei do consumo, por um lado, a lei da sobrevivência, por outro" (PERRONE-MOISÉS, 2004c., p. IX). A primeira transforma Barthes em objeto cultural a ser descartado; a segunda o coloca entre os mortos que os vivos, que por assim dizer veem no pai um entrave à construção da própria fama, apressam-se a enterrar. No contexto do presente ensaio, seria talvez necessário acrescentar que o limbo pode também ser o resultado de uma proposta de ética de leitura que, marcada pelo radicalismo de um momento histórico de ascensão das vanguardas, feriu com violência a hegemonia de um discurso cultural.

No caso de Foucault, a sofisticação histórica, o rigor teórico e a rejeição do discurso radical de vanguarda garantiram à ética de leitura proposta à sobrevida que, em certa medida, foi negada a Barthes. Um bom começo para pensar essa ética é o entendimento que tem Foucault do relacionamento entre autor e texto. Enquanto para Barthes a pergunta a respeito de quem fala no texto de Balzac deve ser respondida em termos da ausência de uma origem, para Foucault, essa ausência não pode ser apenas constatada, mas deve ser também examinada enquanto um espaço vazio problemático porque tratase de esvaziamento que tem consequências importantes em termos de um deslocamento de poder. A 
pergunta apropriada a ser feita não é “quem fala?”, mas antes “o que importa quem fala?”, extraída de um texto de Beckett (FOUCAULT, 2009, p. 265). E a pergunta é de fundamental importância porque "é preciso descobrir, como lugar vazio - ao mesmo tempo indiferente e obrigatório -, os locais onde sua função é exercida" (FOUCAULT, 2009, p. 265).

Esvaziado de seu lugar tradicional, o autor continua a atuar em um campo de distribuição de poder em que a prática da violência ou da opressão só desaparece em certos espaços para reaparecer em outros. Ou então, de forma talvez mais insidiosa, aparece e desaparece no espaço por excelência de seu desaparecimento, ou seja, na escrita. "Na escrita”, diz Foucault, "não se trata da amarração de um sujeito em uma linguagem; trata-se da abertura de um espaço onde o sujeito que escreve não para de desaparecer" (FOUCAULT, 2009, p. 268). Como ler um texto em que o autor é uma força ativa que, aparecendo e desaparecendo sem cessar, na realidade torna-se imortal? Como responder a esse poderoso desaparecimento que nunca deixa de se manifestar em exercícios de poder de inclusão e de exclusão a respeito, por exemplo, de quem pode escrever e de quem pode somente ler, ou sobre quem decide a respeito de cada um dos casos?

O leitor atento a essas armadilhas de poder e controle poderia ser talvez caracterizado como um leitor curioso, desconfiado (inclusive de si mesmo) e dedicado a uma prática de leitura sempre marcada pela suspeita. É que a leitura passa a ser vista, nesse contexto, como o que Foucault chamou de "tecnologia de dominação”, ou seja, aquela que, dispersa em mecanismos de normalização que saturam qualquer grupo social, “determina a conduta de indivíduos com o objetivo de direcioná-los para certas finalidades” (FOUCAULT, 1988, p. 18). Boa parte da obra de Foucault é dedicada ao estudo desses mecanismos que operam de forma disciplinar em discursos e instituições: nas prisões, nos hospitais, nas escolas, nos discursos da medicina, da psiquiatria e da loucura. E operam também nas práticas de leitura definidas em campos normativos de poder que produzem sujeitos-leitores através do uso sistemático de tecnologias disciplinares de controle.

A ética da leitura da suspeita que Foucault pratica em seus escritos e que deveria motivar os que nela acreditam supõe um leitor em constante questionamento da sua condição enquanto sujeito-leitor, das formas que o constituíram enquanto tal, do relacionamento que estabelece com um texto. De que forma, por exemplo, deve o leitor comportar-se diante dos textos canônicos, dos clássicos, do autor enquanto gênio e produtor da abundância inesgotável de sentido? Seria necessário, por exemplo, olhar para o seu valor cultural acumulado ou, ao contrário, para o seu poder de inclusão e exclusão de textos?

Assim entendido, oleitoré, sobretudo, um curioso. “A curiosidade”, diz Foucault em “O Filósofo Mascarado”:

foi estigmatizada pelo cristianismo, pela filosofia, e até mesmo por uma certa concepção da ciência. A curiosidade é entendida como futilidade. Mas eu gosto da palavra. Para mim, sugere algo bem diferente. Lembra "cuidado"; faz pensar no cuidado que se tem com o que existe e com o que poderia existir; um senso apurado da realidade, mas que não é jamais imobilizado diante dela; uma prontidão para perceber que o que nos cerca é estranho e singular; uma certa determinação para descartar os caminhos familiares do pensamento e para olhar as mesmas coisas de forma diferente; uma paixão para captar o que acontece agora e o que desaparece; uma falta de respeito pelas hierarquias tradicionais a respeito do que é importante e fundamental. (FOUCAULT, 1988a, p. 325)

Essa apologia da curiosidade, certamente uma das características principais do pensador que reflete sobre as funções autorais, aponta para uma ética de leitura que não deveria ser esquecida, se não por 
outro motivo, pelo menos porque, comprovadamente, já surtiu bons efeitos em pensadores por ela influenciados. Edward Said é um exemplo, entre tantos outros. Não seria descabido afirmar que um livro como Orientalismo, por exemplo, dificilmente apareceria na forma como apareceu se Said não tivesse absorvido em profundidade, principalmente nos seus anos iniciais de formação e em livros como Beginnings, a obra até então conhecida de Michel Foucault.

Se, por outro lado, a importância de Barthes não foi tão significativa, não deve, entretanto, ser ignorada. A ética de leitura do autor de O Prazer do Texto poderia talvez ser entendida como uma ética do prazer, contanto que se tenha um certo cuidado na definição do termo. Em Barthes, o prazer nunca é simplesmente o prazer do corpo de quem escreve, mas um prazer voltado para uma revolução na cultura, no saber, no ensino e nas práticas de leitura. E, se esquecermos por um momento o gesto iconoclasta que acompanha tal prazer, não estaria ele muito distante do que Foucault chamou de "curiosidade".

\section{Referências Bibliográficas}

BARTHES, R. Análise Textual de um Conto de Edgar Allan Poe. In: . A Aventura Semiológica. São Paulo: Martins Fontes, 2001. . Sobre Racine. Trad. Antonio Carlos Viana. Porto Alegre: L\&PM, 1987. Sade, Fourier, Loyola. São Paulo: Brasiliense, 1971. . Da Obra ao Texto. In: . O Rumor da Língua. São Paulo: Martins Fontes, $2004 a$. A Morte do Autor. In: . O Rumor da Língua. São Paulo: Martins Fontes, $2004 b$.

BENNET, A. The Author. New York: Routledge, 2005.

BOOTH, W. C. The Rhetoric of Fiction. Chicago: The University of Chicago Press, 1983.

EAGLETON, T. Criticism and Ideology. London: Verso, 1976.

. Literary Theory: An Introduction. London and Minneapolis: The University of Minnesotta Press, 1983. FOUCAULT, $M$. The Masked Philosopher. In: . Politics Philosophy, Culture. New York: Routledge, 1988. . Technologies of the Self. Amherst, Massachusetts: University of Massachusetts Press, 1988. . O que é um autor? In: . Estética, Literatura e Pintura, Música e Cinema. Rio: Forense Universitária, 2009.

IGOE, V. Early Joyceans in Dublin. Joyce Studies Annual, vol. 12, Summer, 81-99. New York, 2001. LACAN, J. Écrits I. Paris: Éditions du Seuil, 1966.

MARX, K.; ENGELS, F. A Ideologia Alemã. São Paulo: Martins Fontes, 2001. PERRONE-MOISÉS, L. Prefácio. In: BARTHES, R. O Rumor da Língua. São Paulo: Martins Fontes, 2004c. ROSE, M. Authors and Owners: The Invention of Copyright. Cambridge: Harvard University Press, 2002. WHITE, H. The Culture of Criticism. In HASSAN, I. Liberations. Middletown, Connecticut, Wesleyan University Press, 1972.

\section{Recebido em: 20/02/2014 Aceito em: 23/04/2014}

Referência eletrônica: BELLEI, Sérgio Luiz Prado. A Morte do Autor: um retorno à cena do crime. Rev. Cria. Crít., São Paulo, n. 12, p.161-171, jun. 2014 Disponível em: <http://revistas.usp.br/criacaoecritica〉. Acesso em: dd mm aaaa.

DOI: http://dx.doi.org/10.11606/issn.1984-1124.v0i12p161-171. 